ISSN: 2162-3104 Print/ ISSN: 2166-3750 Online Volume 6, Issue 1 (2016), pp. 52-72 (C) Journal of International Students http://jistudents.org/

\title{
International Students, University Health Centers, and Memorable Messages About Health
}

\author{
Heather J. Carmack \\ James Madison University (USA) \\ Shireen Bedi \\ Northern Virginia Community College (USA) \\ Sarah N. Heiss \\ University of Vermont (USA)
}

\begin{abstract}
International students entering US universities often experience a variety of important socialization messages. One important message is learning about and using the US health system. International students often first encounter the US health system through their experiences with university health centers. The authors explore the memorable messages international students receive about using university health centers. Participants identified three important messages: (a) the insurance imperative, (b) triaging your own health, and (c) passing the TB "test". These messages help to socialize international students, but also create confusion because of ambiguity and assumption of previous knowledge.
\end{abstract}

Keywords: communication, international students, university health centers, memorable messages

International students are enrolling in US colleges and universities at an increasing rate. A 2014 report by the Institute of the International Education (IIE) and U.S. Department of State's Bureau of Educational and Cultural Affairs found that during the 2013-2014 academic year, 886,052 
international students were enrolled at US colleges and universities (IIE, 2014). As newcomers to a new country and a new organization (the university), international students often experience culture shock about every aspect of their new lives (Lin, 2006). This culture shock, or anxiety resulting from unfamiliar experiences on cultural travelers (Zhou, JindalSnape, Topping, \& Todman, 2008), often results in added stress and negative health impacts (Shaikh \& Jean-Pierre, 2006). International students might turn to a number of systems to help alleviate stress and address health issues, including the university health center (UHC). An important organization on university campuses, UHCs provide a number of services, including wellness exams, psychological treatment, vaccinations, and referrals to local physicians.

Like US university students, international students have to adjust to their new roles as university students. For international students, the stress of the transition to US university life is coupled with additional stresses associated with learning about the culture, often resulting in "culture fatigue" (Xiaoqiong, 2008). Culture fatigue can manifest in a variety of ways which impact international students' health, including insomnia, change in eating habits, mental health distress, and stress (McLachlan \& Justice, 2009).

The purpose of UHCs is to help students deal with the physical and mental ramifications of university life; however, many students do not often seek out UHC services (McLachlan \& Justice, 2009). Kwan and colleagues (2010) found that although students trusted information from the UHC, they were still more likely to seek out information from the Internet even though believability of information was low. Believability of health information, coupled with hesitation of seeking out help, might become a significant disadvantage for international students who are sick (Misra \& Castillo, 2004). Unfortunately, some stressors of university life are connected directly to the UHC. Cheng (2004) identified a number of frustrations and stressors associated with using UHCs, including frustrations with the lack of control over their own health care and the uncertainty associated with using the system. Interestingly, most of the research examining international students' use of university health services is focused on mental health and counseling (e.g., Hyun, Quinn, Madon, \& Lustig, 2007; Mori, 2000) and reports why students should use these services but often do not. For this study, we are focused on the health center, not counseling services because this is a separate service not associated with the health center.

The information international students receive about seeking out and receiving health care while at a university might be communicated to international students during a common socialization practice: international 
student orientation. During international student orientation, students are often presented with a number of memorable messages about expected behavior, norms, and rules to help them assimilate to US culture and university life (Fischer, 2011). Messages about UHCs present a unique communication experience because of the understudied nature of both international students and UHCs (Russell, Thompson, \& Rosenthal, 2008).

\section{LITERATURE REVIEW}

As new students to the US university system, international students must make sense of multiple new experiences and cultures. An important communicative experience for newcomers, organizational socialization is concerned with the social processes by which individuals become integrated into an organization (Jablin, 1982). The process of entering into a new organization is filled with uncertainty and ambiguity (Louis, 1980). One primary way organizational members manage uncertainty and ambiguity is through the use of memorable messages. Memorable messages convey information to newcomers about the norms, values, expectations, and rules of the organization and how to enact their roles in the organization (Holladay, 2002). These messages also help newcomers assess their own behavior throughout the socialization process, especially if their behavior violates or exceeds expectations (Butler Ellis \& Smith, 2004; Smith \& Butler Ellis, 2001; Smith, Butler Ellis, \& Yoo, 2001). Memorable messages often highlight issues of insecurity, ambiguity, and uncertainty (Knapp, Stohl, \& Reardon, 1981); newcomers, then, must find ways to address these uncertainties in order to integrate into the organization (Stohl, 1986).

There are several key characteristics of memorable messages which make them different from other messages newcomers receive (Stohl, 1986). First, memorable messages often take place at important moments of the socialization process; for international students, this might occur at new student orientation and international student meetings. Second, the messages must impact organizational members' lives long after they heard the message. These messages are usually serious (Ford \& Ellis, 1998) and can come from a variety of organizational veterans, supervisors, or other organizational members familiar with the organization (Noland \& Carmack, 2014). This helps newcomers to retain the messages. Third, memorable messages must be easy enough to remember that they can be quickly recalled when needed. For instance, in the event an international student needs to seek care, he or she should be able to quickly remember the protocol for using the university health center. 
Researchers have explored memorable messages in a number of organizational settings and issues (Barge \& Schlueter, 2004; Stohl, 1986), including work-life balance (Medved, Brogan, McClanahan, Morris, \& Shepherd, 2006), and volunteerism (Steimel, 2013). Memorable messages about university life (Dallimore, 2003; Nazione et al., 2011; Wang, 2012) have primarily focused on how first year students transition to university life; however, this research is focused exclusively on native US students, not international students. More recently, scholars have also examined memorable messages in health, focusing on cancer (Smith et al., 2009a; Smith et al., 2009b), difficult death conversations (Holladay, 2002; Keeley, 2004), flu prevention (Miczo, Danhour, Lester, \& Bryant, 2013), and nursing (Noland \& Carmack, 2014; Ford \& Ellis, 1998). What is missing is an exploration of the messages these newcomers receive about seeking health care on a college campus. The messages international students receive and remember about how to seek care on college campuses are an important part of the socialization process and how international students use health care while in the United States.

To date, scholars have been relatively silent about the communicative practices associated with UHCs, with the exception of Cheng's (2004) general examination of international students' perceptions of UHCs. Health researchers, although often turning to college students to serve as participants in their own studies, do not often focus specifically on students' health or their use of health services (Kwan, Arbour-Nicitopoulos, Lowe, Taman, \& Faulkner, 2010). Moreover, a number of health studies on international student health hint at the importance of communication in their use of UHCs (Donald, 1985; Ebbin \& Blankenship, 1986; Miller \& Harwell, 1983; Sharif, 1994, 1998); however, they do not specifically address the communication international students receive about health care and UHCs. Given the potential impact of memorable messages about health care on international students' understandings of US health care and use of UHCs, we are guided by the following research question: What messages do international students receive about seeking care at the university health center?

\section{RESEARCH METHOD}

This article is part of a larger research project exploring how international and US students learn about, use, and evaluate university health systems. Data collection began once the authors received university IRB approval for the project. The research project was conducted at a large Midwestern university with approximately 21,000 students enrolled each year. Approximately 1,136 of those students are international students 
representing 76 countries.

\section{Participants}

All international students are required to have health insurance and are able to make appointments at the university's health center (referred to in this article as $\mathrm{T}$ Health). $\mathrm{T}$ Health only treats physical issues; students seeking mental health treatment were directed to a separate counseling center on campus. International students are required to buy the university's student health insurance plan. The only students exempt from this rule are Saudi Arabian students who have a separate health insurance plan through their university (because of a joint engineering program). The university's student health insurance plan covers $100 \%$ of wellness visits at T Health, reduced costs for other visits, procedures (including labs and x-rays), and prescriptions. The university's health plan covers up to $80 \%$ of student visits to the university affiliated hospital. Furthermore, Up to $40 \%$ of visits to the non-university affiliated hospital in town are covered.

Students were primarily recruited through introductory communication and introduction to university life classes; however, the researchers also relied on snowball sampling techniques as international student participants often told others about our project. A total of 21 students participated in this study: 7 males (33\%) and 14 females (67\%). Ages ranged from 19 to $27(M=21.52)$. We had a variety of nationalities represented in the focus groups, including China $(n=7)$, South Korea $(n=$ 5), Saudi Arabia $(n=3)$, Malaysia $(n=2)$, Mauritania $(n=1)$, Morocco $(n=$ $1)$, Vietnam $(n=1)$, and Mongolia $(n=1)$.

\section{Data Collection and Analysis}

The first and second authors conducted four focus groups, with size ranging from three to seven participants $(M=5)$. Standard focus group procedures were followed (Morgan, 1988; Stewart \& Shamdasani, 1990). We used a semi-structured interview protocol with questions focusing on what participants knew about the US health system before coming to the university, how the US health system was similar and different from their home nation's health system, how they learned about the university's health system, and their experiences with the university's health system. Semistructured protocols present the interview as a co-constructed experience and allow other issues to emerge during the interview (Heyl, 2001). We probed participant answers and noted nonverbal agreement or disagreement by other participants. Saturation was reached after three focus groups; however, we conducted one more focus group to verify saturation. The interviews, which were audiotaped and transcribed, lasted approximately 1 
hour each, and resulted in 60 single-spaced, typed pages.

Data were analyzed using a thematic constant comparative method of data analysis (Glaser \& Strauss, 1967). We individually read over the focus group transcripts several times to gain a complete understanding of participants' experiences and to ensure that any potential themes were grounded in the data. We open-coded the data individually, identifying potential themes that emerged (Strauss \& Corbin, 1998). We then met to discuss the potential themes, noting and integrating potential themes. Memorable messages emerged as a theoretical framework during the analysis process. After identifying common themes that emerged from the data, we identified repeated and particularly illustrative comments representing the themes (Charmaz \& Mitchell, 2001). Quotations from participants, who are identified with pseudonyms, underscore the themes and deepen the analysis. We decided to use Western names for pseudonyms as many of our participants use a Western moniker while attending the university. Except in a few instances, we have maintained the participants' comments verbatim rather than edit for grammar.

\section{RESULTS}

Memorable messages about US health care and using the university health center heavily influenced how participants made sense of the US health care system. All of the memorable messages received and remembered by our participants spoke to issues of economics and the cost of health care. Participants identified three memorable messages: (a) the insurance imperative, (b) triaging their own health, and (c) passing the TB "test".

\section{Insurance Imperative}

One overarching message influenced participants' understanding of the university health system and US health care: the need to have insurance. As Rena succinctly stated, "To be here, we have to buy insurance." Participants reported not fully understanding the message because of the lack of explanation on how to use the insurance and conflicts between their university's policy and prior cultural experiences with health insurance.

One way participants made sense of the university's insurance plan was by comparing it to their home countries' insurance plans. This helped many participants reconcile the differences. As Ivan explained when discussing the differences between his home country's insurance plan and the plan offered by the university, 
The government pay for the health care for international student as well. And for here, we need to buy insurance and University insurance only covers certain amounts. And we still need to pay when we go to the hospital, after we buy insurance. Completely different.

Like Ivan, Lydia compared her understanding of US health care to her home country's health care.

In China we pay insurance and we go to the hospital if we need a surgery. The company will pay for us, covers the pay. But here the insurance only covers the clinic fee. It's like, if you have a knee surgery you still have to pay for it, and it's very expensive.

Lydia further explained how it is important for her to know this difference in case she ever needs to have surgery in the United States.

Participants were quick to point out, however, that the insurance message is not always communicated clearly. Although the university explained that having insurance is important and required to be a student at the university, the university and $\mathrm{T}$ Health did not explain what is required to use the insurance. A key example of this was the confusion associated with insurance cards, as explained by Maura:

Most of my international student friends, they just don't know what's the insurance for. And even they just get the insurance card and the little discount two cards. There are like two things. They just don't know why they're receiving it and what's this for, even though they participated in the orientation and everything. And one of my friends, he just threw it away. Because he doesn't know what it is, just send it to our mailbox. So he thought he was just throwing out junk, so funny.

Dan had a similar experience, telling us, "The insurance card is sent to me through the mail. I didn't know that so I just throw out.” Maura's and Dan's comments underscore how a simple part of the message was not communicated clearly.

Participants also did not know or understand how displaying an insurance card could impact payment for care. Sue and Mika engaged in an interesting conversation about a recent visit Sue made to the local hospital:

Sue: I went to the emergency room in [local hospital]. At the time I don’t have an insurance card, I don’t have anything. I just go there. 
Mika: You didn't bring it with you, right? You didn't bring it but you have one?

Sue: You bring your insurance card always?

Mika: Yes. On the card it said you should carry it with you all the time.

Sue: I didn't have that one so I just go there. And the payment is very different in Korea, because if you go to the emergency room you just pay that night. But I didn't pay anything at the time. I don't know why. It's very complicated.

Sue and Mika's conversation is an excellent example of how this part of the insurance message is not effectively communicated to students. The differences in many of their home countries' approach to health care, insurance, and payments influence their understanding of this message.

The lack of clarity about the insurance imperative message lead to frustration by participants about the high cost of health care even with insurance and having to pay for insurance but not using it. Many of the participants said they were apprehensive about getting the university health insurance because of the high cost of health care costs in the United States. Anne explained, "We have to buy here. Before I came here, I only heard that the health system is more advanced and the dental medical is really expensive, and the dentists are a lot."

The fear of the high cost of health care is further exacerbated by the fact that many of the participants did not understand that purchasing the university health insurance guaranteed that their visits would be covered. Anne tells the story of her roommate who learned about this discrepancy in the message:

Yes, my roommate also thinks that. She didn't know that she has to pay, and she got this bill after a month and a half after she x-rayed [at T Health], and it was like \$93. She was like, "Do I have to pay this money?” She was so confused, and she got mad, too.

Participants were adamant that the university and $\mathrm{T}$ Health explained that they needed health insurance, but did not explain that the health insurance would not cover all their care at $\mathrm{T}$ Health or that they would receive bills.

Participants also expressed frustration with the lack of clarity associated with the insurance imperative message because the university and T Health did not explain why international students had to pay for insurance when they did not use it or it did not cover all their care. For participants, the cost of the student health insurance was too high and the university did 
not explain enough to justify the cost. Kate went into detail when explaining her frustration:

Before I came here I know that I'm going to have insurance and student insurance. And then, it's like \$500-something for international students, so I thought it's going to cover something, but it was different. I went to $\mathrm{T}$ Health one time and they checked my body once and then got medicine, and then they don't cover anything. Maybe like 50 percent is covered, the medicine, but it didn't cover anything. And all the international students that I met who've been to T Health, they said, "What's the health insurance for? We're just paying $\$ 500$ every semester, and what's that covering for?” There's a lot of confusion.

Kate's comments clearly illustrate her frustration with the insurance message and that there is not enough of a balance between cost and coverage. Beth also expressed the frustration of paying for insurance that she did not use.

The insurance is really expensive and they don't really use it a lot. That maybe they just get checked once or a couple times during one semester. So they said they are basically paying for nothing. They didn't benefit a lot from the insurance.

For participants, the overall message of an insurance imperative was memorable; however, the simplicity of the message frustrated many of the participants because it did not address the complexity of the US health insurance system and using it at $\mathrm{T}$ Health.

\section{Triaging Your Own Health}

A second memorable message our participants received was that they had to triage their own health to determine when to seek treatment at $\mathrm{T}$ Health, when to seek treatment at the local hospital, and when to self-treat. The need to triage was based on confusion about where to seek services, for what health issues to seek care, the cost of services, and the extent of insurance coverage. Participants reported receiving conflicting information from $\mathrm{T}$ Health about whether to visit $\mathrm{T}$ Health, go to the local hospital, or treat themselves.

Participants were reluctant, and in some cases, apprehensive about triaging their own health because they are not knowledgeable about health and because they had been socialized in their home countries to always visit a hospital when sick. Maura talks about the information she received from $\mathrm{T}$ 
Health administration at the international student orientation about determining where to go:

We had orientation in the ISS [International Student Services] for international students. And they said, "We have T Health, it's a hospital at [our university]." And they said, "Don't go there if you have headache or if you get a cold. Just don't go there. If you have a serious thing, just go there.” Otherwise, just don't go there. That's what I remember.

Dina also received similar information from her friend, "She advise me, don't go to them. Only if you are very sick, then go just to T Health.” Both Maura and Dina's comments underscore the message that students should only go to $\mathrm{T}$ Health when they are extremely sick. This stands in contrast to many of the participants' experiences in their home countries where everyone visits the hospital (which also houses doctors' clinics and pharmacies) when ill. For Maura and Diana, triaging was more difficult because they believed $\mathrm{T}$ Health was a hospital and did not know the difference between a hospital and a health center.

Triaging becomes difficult when students are not aware of what facilities are available to visit or what illnesses are treated at each facility. Both Mika and Rena expressed frustration of not knowing where to go for care. Mika stated, "I think if I'm sick I have to go to the hospital. I don't know. I'm not sure if go to hospital or T Health.” Rena pointedly asked the focus group participants, “Actually, in my case, I don’t know. Where should I go if I am sick?” This promoted a discussion between the moderator and participants about all of the different places in town where participants could seek care, such as Urgent Care, and how to triage their health issues. Kate explained,

It is really good if we knew what kind of treatment $\mathrm{T}$ Health can give us. Maybe not colds, but if I have real emergency, I should go to T Health or [the local hospital]? I think it would be really good if T Health tell which kinds of illness that they can treat.

Providing this information not only would help the international students determine where to go to seek treatment, but also to begin to determine how the US health care system categorizes illness, which might be different from how participants' home countries categorize sickness.

In the course of triaging their own health care, some participants even decided to not receive any treatment or health care because it was too 
confusing or expensive. For Tana, this confusion is what keeps her from visiting T Health.

I know the people there are very kind to me at T Health, but I'm still trying to avoid because I'm not sure. Just because I don't have such knowledge about what I have to be charged or not. So I'm trying to avoid it actually.

Some participants reported avoiding $\mathrm{T}$ Health and found other means of receiving health care while in the US. Instead of visiting $\mathrm{T}$ Health, participants sought out alternative ways to treat their health issues. Many participants turned to a local pharmacy and grocery superstore for advice to avoid T Health, as Marc explained,

Sometimes I avoid it, too, and just get medication by asking somebody, "What is good for?" For example, flu or something. You know, and just get medication. For example, the flu shot. I got the flu shot, but I didn't go to T Health because I thought, it's going to be more. So I went ahead and got it in another clinic for \$20. So I mean, yes. There is that feeling of avoidance, trying to stay away as much as you can.

This message of triaging health care by seeking care from other venues was reinforced by participants' friends, who also used other venues. When discussing why she usually visits a local grocery superstore to get medicine, Kate uses a friend's experience to explain her decision:

Kate: In my case, my friend is sick and she just asked others which medicine is good and go to Wal-Mart and buy the medicine. That's all for her.

Moderator: Not even entering into T Health?

Kate: Yes.

Moving beyond visiting outside health care venues, several participants were so hesitant to use their university insurance or seek care at health care facilities that they turn to their home countries' approach to health care. Anne succinctly explained how she treats herself.

Anne: And I brought a lot of kinds of medicine with me here.

Moderator: So were you hoping to use that medicine instead of buying it here?

Anne: Yes. I won't buy it. 
Anne's comment does not state that she completely rules out using US health care remedies, but she prefers to use her home country's medicine if she has to treat herself. Karl was advised by his friends to avoid receiving care in the United States:

Some of my friends told me, in case you have to have surgery, it's better to go back home or other country and do it and then come back, because our insurance doesn't cover everything and it would be very expensive.

Although Karl's statement addresses an extreme health issue, his comment underscores how participants receive messages that further enforces the message that international students must learn to triage their own health care rather than visit T Health.

\section{Passing the TB “Test”}

The final memorable message participants identified was that international students had to pass the tuberculosis (TB) "test" to be considered members of the university. All international students must receive the TB skin test. This test determines if an individual has an immune response to the TB bacteria. Individuals who receive a "positive" test result have developed immunity to the TB bacteria. Individuals who do not receive a positive test result must then get an X-ray to determine if they have TB. International students must receive a positive result on the TB test to enter the university and take classes. Although all participants remembered hearing messages that they have to take and receive a positive TB test, they said that the messages regarding how to pay for the test and how to get an acceptable test result was not explained.

An important part of this message is that the TB test is partly covered by the university insurance. However, as participants point out, this message is misleading. As Ivan pointed out, the price of the TB test is much higher than in his home country, which was a surprise to him: "I remember the first time when I came, they took me to T Health for the TB test, and I pay $\$ 100$. For me it was very expensive compared to I used to pay back home, about $\$ 5$ or $\$ 10 . ”$

Participants expressed frustration with the TB experience because the message they receive from the university does not fully explain to international students that not all of the test will be covered. Dan and Julie engaged in an insightful conversation about the hidden costs of passing the TB test: 
Dan: Not everything was covered, though. Because I had to take the TB test, and then when I went back a couple of days later they told me to do the $\mathrm{x}$-ray. And they charged me $\$ 70$ and they take that out of my pocket. $\$ 70 \mathrm{x}$-ray.

Julie: Because that is a separate fee. They may have thought that you have some problem in your lung.

Dan: Yes, they took the x-ray and said there's nothing wrong, so just go ahead. They charged me $\$ 70$ for nothing, basically.

Moderator: They didn't tell you why? Did they ask you?

Dan: A doctor said you have to have the x-ray.

Dan and Julie's conversation clearly illustrates the confusion associated with what is required to pass the TB test. Dan thought that all of the procedures associated with the TB tests were covered, not just the original TB test. Frustration regarding the costs associated with passing the TB test was echoed by Tana:

At Chinese student orientation, the President told us to have this TB test, and we had it. And the people there were very kind, but I had to have this test three times because my blood is too thick. Then had to drink water and come there again, and they tested me again. And really we know that this fee could be covered on your insurance, so we didn't notice the bill. They actually charged me and there is a due date, and I was fined.

Tana's narrative illustrates how the frustration in not associated with the test, but with the hidden costs associated with the required test as well as with the way the university does not explain how students have to pay for the tests. Tana's story serves as an example of how different cultural approaches to insurance and paying for health care clash with Western approaches.

Participants reported having to take the TB test again at T Health even if they had already received a positive test result from TB tests administered in their countries. This message reinforces the idea that to pass this "test" and become a member of the university, international students must take the TB test at T Health. Mari explains that she thought she was being proactive and saving herself money by receiving the TB skin test before she arrived in the US. Julia had a similar experience:

Oh, I've taken twice. This one is my second one. Because I thought this university would accept the TB test result from the institute I received my TB test, the former one, in China. But it turned out, it 
doesn't work. So I got a TB test in China, and then after I arrived here, I learned from the orientation that I had to take another one. So I got two shots.

The message that international students can only pass the TB test if it is administered at $\mathrm{T}$ Health is not always clearly articulated to or understood by students, as illustrated by Julia's narrative.

\section{DISCUSSION AND CONCLUSIONS}

International students new to a university must figure out how to successfully meet their health care needs while away from their home countries. Driven by a fear of the cost of US health care, international students in this article often struggled with determining when to use the UHC and when to engage in self-care. UHCs, and greater US health care system, served as the proverbial "entrance gate" to the university, where international students must successfully pass the TB "test” before being able to call themselves university students.

A major tension underlies the participants' ability to successfully navigate the university health system: the differences between the US approach to health and their home countries' approach to health. The university made it clear before arriving to the university and during international student orientation that international students must have university health insurance and use the UHC. Many of the international students expressed frustration with the different rules and procedures associated with the university center (being charged for not cancelling an appointment, not being told what was covered by the university student insurance, etc.).

These frustrations lead the students to stop using the university health center altogether and seek out their own remedies or avenues for health. Many of the students reported going to a local Asian market and pharmacy where they could get herbs and treatments with which they were familiar rather than buying medication at the university center pharmacy. Others talked about getting dental, eye, and medical care before coming to the US to avoid the cost. Some students reported not using the UHC at all because they were unfamiliar with health centers. Although international students might be from countries that have different health systems and beliefs, this does not mean that the students are not willing or interested in learning how to successfully use the US health system. Understanding the rules, scripts, routines, and procedures associated with the UHC is key to 
helping international students make sense of their health experiences and be members of the university.

This does not mean, however, that international students did not have access to information about how to use the system. The international students turned to university veterans, in this case other international students who had been studying at the university for a longer period of time and could provide that information. It is not uncommon for newcomers to look to veterans to help make sense of organizational experiences, especially when ambiguity is present. These information seeking and gathering moments serve as informal socialization experiences where newcomer international students learn about how to use the UHC and make sense of the US health system. These informal socialization experiences can become problematic, however, when veterans do not use the UHC or understand how the system works. When this happens, new international students might receive conflicting messages and will be forced to determine which message is the appropriate memorable message.

\section{PRACTICAL APPLICATIONS}

There are a number of recommendations for how university health clinics and international student services can work together to better educate international students about using university health clinics and create more culturally competent health spaces. First, international student university orientations need to provide more detail about using the university health clinic. It is not enough to simply tell students that is the campus health facility or the campus "hospital"; they need to know how the clinic works in order to successfully navigate it. As recommended by several of the participants, university health clinic staff could offer workshops for new international students to help negotiate the health clinic or give more detailed tours of the center. Additionally, simple checklists could help international students bring all of the needed health documentation, including insurance cards, with them to appointments.

Since university orientation is not the only place international students receive information about the university health clinic, international student service department staff need to work more closely with the university health clinic staff to make sure international students receive information before arriving to campus. Rather than simply sending the standard health insurance brochure or insurance cards to students with no additional explanations, both groups need to work together to provide international students with understandable materials before arriving to the 
US in order to ensure that these students are prepared and to help alleviate some of the health culture shock international students experience.

\section{LIMITATIONS AND FUTURE DIRECTIONS}

There are several limitations. First, the sample size was small. This small sample size is tempered by the fact that we did have a wide variety of nationalities represented at the focus groups and reached saturation quickly. Additionally, although we promoted the project through several different channels, participants were mainly from Asian and Middle Eastern countries. We did not have the voices of international students from European, South American, or North American countries. All were students at the same large Midwestern public university which has a vibrant international student population, meaning there are programs in place to help students transition and use the health services. International students at other types of institutions, such as small or medium universities, private colleges, community colleges, and schools with low international student attendance might have different experiences with their university health centers. Given that there is a lack of research on UHCs and international student health, scholars need to devote more time to studying the communication issues present in international students' knowledge and use of UHCs.

Second, this paper focuses only on one particular educational stakeholder: international students. Other voices involved in helping international students transition to the university and the health center, such as health center staff, international student services staff, and administrators, are missing from this analysis. The exclusion of these voices was intentional; we wanted to focus on how international students made sense of their experiences. Individuals working for universities might have a different understanding of international students' knowledge and experience with UHCs. The study of university international student orientations is also needed to explore what information is provided and how that information is communicated to international students. Third, the role of veteran international students on helping new international students make sense of memorable messages cannot be ignored. Our analysis underscored how international students often turned to other international students with more experience to help make sense of the ambiguous UHC messages. Future research exploring the support networks used by new international students to learn about health care is warranted.

This article serves as a call for the need to study issues of health and culture on university campuses. First, many participants questioned the 
cultural competence of their providers. With UHC providers seeing a variety of domestic and international students with varying cultural beliefs about health, research exploring UHC providers' cultural competence is needed. Moreover, the findings of this study underscore the need to research and identify the best ways to communicate differences between health centers, hospitals, emergicare clinics, and other facilities. Second, there may be a gendered use of university health centers. Several female participants mentioned during every visit to $\mathrm{T}$ Health they were asked questions about menstruation cycle and possibilities of pregnancy, which is not common practice in many Asian and Middle Eastern countries. Several of the female participants stated that these questions were so off-putting that they did not return to the UHC.

As the number of international students at US universities continues to grow, every part of the university needs to engage in cultural competence, including the UHC. Practitioners, program administrators, and scholars will need to rethink their approaches to how important health information is communicated to international students, ensuring they know the options available to them so that they can make the best health care decisions.

\section{REFERENCES}

Barge, K. J., \& Schlueter, D. W. (2004). Memorable messages and newcomer socialization. Western Journal of Communication, 68, 233-256. doi:10.1080/10570310409374800

Butler Ellis, J., \& Smith, S. W. (2004). Memorable messages as guides to self-assessment of behavior: A replication and extension diary study. Communication Monographs, 71, 97-119. doi: 10.1080/03634520410001691456

Charmaz, K., \& Mitchell, R. (2001). Grounded theory in ethnography. In P. Atkinsons, A. Coffey, S. Delamont, J. lofland, \& L. Lofland (Eds.), Handbook of ethnography (pp. 160-174). London: Sage.

Cheng, H-I. (2004). Being ill in a foreign land: International students' perceptions of and experiences with university health services. Kaleidoscope: A Graduate Journal of Qualitative Communication Research, 3, 70-92. Retrieved from http://opensiuc.lib.siu.edu/kaleidoscope/

Dallimore, E. J. (2003). Memorable messages as discursive formations: The gendered socialization of new university faculty. Women's Studies in Communication, 26, 214-265. doi: 10.1080/07491409.2003.10162460 
Donald, F. (1985). Providing health care for international students. In J. C. Naughton (Ed.), Health care for the international student: Asia and the Pacific (pp. 1-8). Washington DC: United States Information Agency.

Ebbin, A. J., \& Blankenship, E. S. (1986). A longitudinal health care study: International versus domestic students. Journal of American College Health, 34, 177-182. doi:

10.1080/07448481.1986.9939634

Fischer, K. (2011, May 29). College adapt to new kinds of students from abroad. The Chronicle of Higher Education. Retrieved from http://chronicle.com/article/Colleges-Educate-a-New-Kindof/127704/

Ford, L. A., \& Ellis, B. H. (1998). A preliminary analysis of memorable support and nonsupport messages received by nurses in acute care settings. Health Communication, 10, 37-63. doi: 10.1207/s153271001_3

Glaser, B., \& Strauss, A. (1967). Discovery of grounded theory. Chicago, IL: Aldine.

Holladay, S. J. (2002). "Have fun while you can," "You're only as old as you feel," and "Don't ever get old!”: An examination of memorable messages about aging. Journal of Communication, 52, 681-697. doi: 10.1111/j.1460-2466.2002.tb02568.x

Heyl, B. S. (2001). Ethnographic interviewing. In P. Atkinson, A. Coffy, S. Delamant, J. Lofland, \& L. Lofland (Eds.), Handbook of ethnography (pp. 369-382). London: Sage Publications.

Hyun, J., Quinn, B., Madon, T., \& Lustig, S. (2007). Mental health need, awareness, and use of counseling services among international graduate students. Journal of American College Health, 56(2), 109118. doi:10.3200/JACH.56.2.109-118

Institute of International Education. (2014). Open Doors 2014: International students in the United States and study abroad by American students at all-time high [press release]. Retrieved from http://www.iie.org/Who-We-Are/News-and-Events/PressCenter/Press-Releases/2014/2014-11-17-Open-Doors-Data

Jablin, F. M. (1982). Organizational communication: An assimilation approach. In M. E. Roloff \& C. R. Berger (Eds.), Social cognition and communication (pp. 255-286). Beverly Hills, CA: Sage.

Keeley, M. P. (2004). Final conversations: Survivors' memorable messages concerning religious faith and spirituality. Health Communication, 16, 87-104. doi: 10.1207/S15327027HC1601_6 
Knapp, M. L., Stohl, C, \& Reardon, K. (1981). Memorable messages. Journal of Communication, 32(4), 27-42. doi: 10.1111/j.14602466.1981.tb00448.x

Kwan, M. Y. W., Arbour-Nicitopoulos, K. P., Lowe, D., Taman,S., \& Faulkner, G. E. J. (2010). Student reception, sources, and believability of health-related information. Journal of American College Health, 58(6), 555-562. doi:10.1080/07448481003705925

Lin, C. (2006). Culture shock and social support: An investigation of a Chinese student organization on a US campus. Journal of Intercultural Communication Research, 35, 117-137. doi:10.1080/17475750600909279

Louis, M. R. (1980). Surprise and sense making: What newcomers experience in entering unfamiliar organizational settings. Administrative Science Quarterly, 25, 226-251. doi:00018392/80/2502-0226

McLachlan, D. A., \& Justice, J. (2009). Grounded theory of international student well-being. The Journal of Theory Construction and Testing, 13, 27-32. Retrieved from http://tuckerpub.com/jtct.htm

Medved, C. E. Brogan, S. M., McClanahan, A. M., Morris, J. F., \& Shepherd, G. J. (2006). Family and work socializing communication: Messages, gender, and ideological implications. Journal of Family Communication, 6, 161-180. doi: 10.1207/s15327698jfc0603_1

Miczo, N., Danhour, E., Lester, K. E., \& Bryant, J. (2013). Memorable messages and the H1N1 flu virus. Western Journal of Communication, 77, 625-644. doi: 10.1080/10570314.2013.776099

Miller, D., \& Harwell, D. (1983). International students at an American University: Health problems and status. The Journal of School Health, 53, 45-49. doi: 10.1111/j.1746-1561.1983.tb04053.x

Misra, R., \& Castillo, L. G. (2004). Academic stress among college students: Comparison of American and international students. International Journal of Stress Management, 11, 132-148. doi: 10.1037/1072-5245.11.2.132

Morgan, D. L. (1988). Focus groups as qualitative research (Qualitative Research Methods Series 16). Newbury Park, CA: Sage.

Mori, S. C. (2000). Addressing the mental health concerns of international students. Journal of Counseling \& Development, 78(2), 137-144. doi: 10.1002/j.1556-6676.2000.tb02571.x

Nazione, S., LaPLante, C., Smith, S. W., Cornacchione, J., Russell, J., \& Stohl, C. (2011). Memorable messages for navigating college life. Journal of Applied Communication Research, 39, 123-143. doi: 10.1080/00909882.2011.556138 
Noland, C. M., \& Carmack, H. J. (2014). "You never forget your first mistake": Nursing socialization, memorable messages, and communication about medical errors. Health Communication [online first]. doi:10.1080/10410236.2014.930397

Russell, J., Thomson, G., \& Rosenthal, D. (2008). International student use of university health and counseling services. Higher Education, 56, 59-75. doi: 10.1007/s10734-007-9089-x

Shaikh, B. T., \& Jean-Pierre, D. (2006). Life in a university residence: Issues, concerns, and responses. Education for Health, 19(1), 43-51. doi: 10.1080/13576280500534628

Sharif, B. (1994). Discussing the needs of a neglected population: Adjustment problems and health issues of international students. Journal of Health Education, 25, 260-265. doi:10.1080/10556699.1994.10603043

Sharif, B. (1998). The forgotten world on campus: Acculturation and health issues of international students. The Health Educator, 30, 11-18. Retrieved from http://www.etasigmagamma.org/healtheducator

Smith, S. W., Atkin, C., Skubisz, C. M., Nazione, S., \& Stohl, C. (2009a). The impact of personal and/or close relationship experience on memorable messages about breast cancer and the perceived speech acts of the sender. Journal of Cancer Education, 24, 129-134. doi: $10.1080 / 08858190902854681$

Smith, S., \& Butler Ellis, J. (2001). Memorable messages as guides to selfassessment of behavior: An initial investigation. Communication Monographs, 68, 154-168. doi: 10.1080/03637750128058

Smith, S. W., Butler Ellis, J., \& Yoo, H-J. (2001). Memorable messages as guides to self-assessment of behavior: The role of instrumental values. Communication Monographs, 68, 325-339. doi: 10.1080/03637750128072

Smith, S. W., Nazione, S., LaPlante, C., Kotowski, M., R., Atkin, C., Skubisz, \& Stohl, C. (2009b). Topics and sources of memorable breast cancer messages and their impact on prevention and detection behaviors. Journal of Health Communication, 14, 293-307. doi: 10.1080/10810730902805903

Steimel, S. (2013). Connecting with volunteers: Memorable messages and volunteer identification. Communication Research Reports, 30, 1221. doi: 10.1080/08824096.2012.746220

Stewart, D. W., \& Shamdasani, P. N. (1990). Focus groups: Theory and practice (Applied Social Research Methods Series, vol. 20). Newbury Park, CA: Sage. 
Stohl, C. (1986). The role of memorable messages in the process of organizational socialization. Communication Quarterly, 34, 231249. doi:10.1080/01463378609369638

Strauss, A., \& Corbin, J. (1998). Grounded theory methodology: An overview. In N. K. Denzin \& Y. S. Lincoln (Eds.), Strategies of qualitative inquiry (pp. 158-183). Thousand Oaks, CA: Sage Publications.

Wang, T. R. (2012). Understanding the memorable messages firstgeneration college students receive from on-campus mentors. Communication Education, 61, 335-357. doi: 10.0180/03634523.2012.691978

Weick, K. E. (1995). Sensemaking in organizations. Thousand Oaks, CA: Sage.

Xiaoqiong, H. (2008). The culture shock that Asian students experience in immersion education. Changing English, 15, 101-105. doi:10.1080/13586840701825378

Zhou, Y., Jindal-Snape, D., Topping, K., \& Todman, J. (2008). Theoretical models of culture shock and adaption in international students in higher education. Studies in Higher Education, 33, 63-75. doi:10.1080/03075070701794833

HEATHER J. CARMACK, PhD, is an assistant professor in the School of Communication Studies at James Madison University. She received her PhD in Communication from Ohio University. Her research interests include communicating about patient safety and organizational policies and practices that impact health decision-making. Email: carmachj@jmu.edu

SHIREEN BEDI, MA, is an instructor in the Department of Communication Studies and Theater Arts at Northern Virginia Community College. She received her MA in Communication from Missouri State University. Her research interests include intercultural communication in healthcare. Email: bedi.shireen@gmail.com

SARAH N. HEISS, PhD, is an assistant professor in the Department of Community Development and Applied Economics at the University of Vermont. She received her $\mathrm{PhD}$ in Communication from Ohio University. Her research interests explore how communication practices shape and are shaped by how publics make sense of health risks and consumption. Email: sarah.heiss@uvm.edu 